\title{
Project team acquiring based on digital footprint
}

\author{
Elena Ganebnykh ${ }^{1, *}$, Olga Fokina $^{1}$, Mikhail Lunyakov ${ }^{2}$, and Irina Milchik ${ }^{3}$ \\ ${ }^{1}$ Vyatka State University, Moskovskaya str., 36, Kirov, 610000, Russia \\ ${ }^{2}$ Moscow State University of Civil Engineering, 26 Yaroslavskoye Shosse, Moscow, 129377, Russia \\ ${ }^{3}$ Vyatka State Agrotechnological University, Oktyabrsky avenue, 133, Kirov, 610017, Russia
}

\begin{abstract}
Project management issues are closely related to a team acquiring. Traditionally considered factors are the level of experience, interest level, personal qualification, availability, and knowledge - do not take into account the interaction of team members. In this regard, the increased conflictogenic situation may complicates communication in the project and reduces its effectiveness. The proposed methodology analyzes the digital footprint of candidates who are the potential project team members in an intracorporate messenger. The analyzed elements are words nominating emotions, words describing emotions and emotive means (emoji, punctuation marks, Caps Lock symbols). Based on the analysis of the digital footprint, the diagnostics of the expected and avoidable characteristics of team members is carried out, a homogeneous environment is formed based on the median indicators. Selected project team members must correspond to discovered indicators or have minimal deviations. This technique can also be adapted for recruiting members into an already established team. Diagnostics must be done in a similar way, the group-specific characteristic must be identified, and suitable candidates should not deviate from the median value by more than 1 point. Thus, there is no model of an "ideal" team, since it is formed in the format of an ideal combination of existing members.
\end{abstract}

\section{Introduction}

The rapid acceleration of information flows and dynamic changes in the external environment are forcing organizations to rebuild their processes towards greater flexibility. In the $60 \mathrm{~s}$ and $70 \mathrm{~s}$ of the XX century, the technology of project activities appeared in the USA and Europe [1], which is characterized by clear goals, limited time and resources, as well as a temporary team [2]. Traditionally, it is believed that the key factor for the success of project management is the presence of a clear predetermined plan, minimizing risks and deviations from the plan, and effective change management. The demand for project management at the present stage of economic systems development is obvious. National and international project management standards describe in detail the methodology of this approach:

\footnotetext{
*Corresponding author: ganebnykh@mail.ru
} 
- ISO 10006:2003 Quality management systems — Guidelines for quality management in projects (adopted in Russia as GOST R ISO 10006-2005 "Quality management systems. Quality management guidelines for design)

- ISO 21500:2012 Guidance on project management (adopted in Russia as GOST R ISO 21500:2014 "Project management guidelines").

National project management standards are also adopted in individual countries, for example APM Body of Knowledge in UK, DIN 69901 in Germany, AFITEP in France, $\mathrm{P} 2 \mathrm{M}$ in Japan, C-PMBOK in China etc. The most common project management methodology in Russia is PMI. The structure of project management system model includes subjects, objects and management processes. The subjects of management include, along with other participants, the project team, on which the final result largely depends.

A project team is a group of people directly working on a project and reporting to the project manager. This is the main element of the project structure, as it is the team that ensures the implementation of the entire idea. This group is created for the duration of the project and is disbanded after its completion. According to PMBOK, project team management includes team acquiring, development and coordination of activities [3]. The most significant stage is the acquiring of the composition and structure of the team, since the competent selection of performers reduces the risks of the project.

While selecting and deciding on team members, the following acquiring project team criteria should be considered:

- Required level of experience at appropriate projects and activities. The project manager gathers all information about current experience level of team member to compare it with the required experience level.

- Interest level. The project manager defines whether team member is interested in participating in project and why.

- Personal qualifications. By means of interviews and questionnaires, the project manager looks at personal skills and talents of team member and measure how this individual team member will work with other project team members.

- Availability. The project manager identifies whether project team member desired for the project is available. The project manager should decide with functional managers on the availability of potential team members.

- Knowledge. The project manager identifies the competency and proficiency of available project team members [4].

By using the acquiring project team criteria, the project manager and members of the project management team select a method of team acquisition. There are several standard acquiring project team methods, including the following (table 1).

Table 1. Standard acquiring project team methods.

\begin{tabular}{|c|l|l|}
\hline$\#$ & \multicolumn{1}{|c|}{ Method } & \multicolumn{1}{c|}{ Description } \\
\hline 1 & Pre-assignment & $\begin{array}{l}\text { This method allows selecting team members in advanced, before } \\
\text { project starts. The method is used in situations when implementation } \\
\text { of project depends on the expertise of specific people who deliver a } \\
\text { competitive proposal to project }\end{array}$ \\
\hline 2 & $\begin{array}{l}\text { Virtual team } \\
\text { building }\end{array}$ & $\begin{array}{l}\text { This method is used when the whole project or a significant part of it } \\
\text { is to be fulfilled by groups of people who carry out their roles and } \\
\text { responsibilities with little or no time spent on face-to-face } \\
\text { communication and collaboration. Virtual teams use electronic means } \\
\text { of communication (such as email and video conferencing) to fulfill } \\
\text { project tasks. A virtual team environment is based on communication } \\
\text { planning, so the project manager needs to ensure virtual teams have } \\
\text { all required communication tools to participate in project. }\end{array}$ \\
\hline 3 & Negotiation & This method allows making staff assignments between multiple \\
\hline
\end{tabular}




\begin{tabular}{|l|l|l|}
\hline & $\begin{array}{l}\text { projects in order to ensure each of the projects has appropriately } \\
\text { competent human resources within the required time frame. The } \\
\text { method entails development and use of delegation and re-assignment } \\
\text { models to make efficient staff assignments considering the benefits } \\
\text { and visibility of competing projects. }\end{array}$ \\
\hline 4 & Acquisition & $\begin{array}{l}\text { This method is used when organizations do not have the in-house staff } \\
\text { needed to complete the project, the staff acquisitions may be net new } \\
\text { resources, consultants, or subcontractors. }\end{array}$ \\
\hline
\end{tabular}

However, whatever the methods of team acquiring, the project manager is always faced with a situation where it is necessary to compare potential participants and choose the most suitable ones. For example, he will have to choose between one who has experience and expertise but little time and poor teamwork skills, and another with less experience but more time and a better attitude. Traditionally project manager has to define criteria to consider: availability, cost, experience, desire to work on the project, competencies, attitude, geography, flexibility of skill set. Based on criteria value and weight project manager identifies the team members.

Back in 1964, McGrath pointed out that different factors (e.g. individual factors, target factors, environmental factors and others) affect the team interaction process directly, and then influence the team performance [5]. Many scholars rely on McGrath's research to construct diagnostic methods that will help to discover the compatibility of factors.

Modern science develops new analytic methods based on digital footprint. The analysis of the employee's digital footprint helps to understand his targets, acceptable and unacceptable behavioral patterns, as well as triggers for effective interaction. The aim of the study is to develop a methodology for acquiring a project team based on the analysis of a digital footprint in the company's internal communication channels.

\section{Methods and Materials}

First of all, for the acquiring of a project team, the coincidence of individual factors is important:

- Neuroticism - how much a person tends to experience negative emotions (anxiety, irascibility, depression). The opposite of neuroticism is emotional stability.

- Extraversion - characterized by the breadth of activity forms in which a person is involved, general initiative and activity, a tendency to quickly and easily make contact and communicate.

- Openness - associated with a person's inclination and interest in creativity, new and unusual ideas, emotionality and active imagination.

- Friendliness - associated with trust and altruistic aspirations of a person, the ability to show compassion for others, decent and polite behavior towards others.

- Conscientiousness - reflects the discipline and hard work of a person, the desire for efficiency and accuracy in their own activities, the severity of a sense of duty.

Diagnostic tools are used to identify the severity of these factors. In our study, we used the McCrae's five-factor theory of personality [6,7].

It is also extremely important to determine the factors of expectation and avoidance in teamwork (table 2). For this, a matrix of 7 factors and their antipodes is formed, and potential candidates rank these factors according to their priority. Among the factors of expectations, $1^{\text {st }}, 2^{\text {nd }}$ and the last places are singled out according to the principle "what is most significant and important for you in teamwork, and what would you put in last place." At the same time, the location of the factor in the last place does not mean that the factor is not important, just while other things being equal, the candidate will give preference to another characteristic. 
Table 2. Expectations \& avoidance in teamwork.

\begin{tabular}{|c|l|l|}
\hline$\#$ & $\begin{array}{c}\text { What is important for a } \\
\text { person in teamwork? }\end{array}$ & $\begin{array}{c}\text { And what, on the contrary, } \\
\text { does he want to avoid? }\end{array}$ \\
\hline 1 & Usefulness & Unproductiveness \\
\hline 2 & Freedom & Oppression \\
\hline 3 & Responsibility & Irresponsibility \\
\hline 4 & Harmony & Toxicity \\
\hline 5 & Energy & Weakness \\
\hline 6 & Order & Disorder, chaos \\
\hline 7 & Competence & Incompetence, stupidity \\
\hline
\end{tabular}

Opposing avoidance factors are set according to the same algorithm. The first and second place in the avoidance factors does not mean that this is the preferred behavior. These are characteristics that a candidate can tolerate more than others.

It is important to avoid confronting in the team people who put the same things in different places. For example, we need to form a team, and we see that many people put in the first place "Usefulness". "I believe that the most important thing in teamwork is how useful a person is for the team and for the project goal." At the same time, many things can be understood as "Usefulness", so it is necessary to draw up a specification of each factor (this is important and necessary for further analysis of the digital footprint). It is important that acquired team will not include people who put unproductiveness (antipode) in the last place. Such people could potentially enter the conflict.

The overall combination of choices should be the most optimal for each specific team. Thus, there is no model of an "ideal" team, as it is formed in the format of an ideal combination of existing candidates. People shouldn't be bothered by conflicting characteristics; the core of the team is consistent.

Factors can be assessed without a diagnostic survey based on digital footprint analysis. Corporate communication channels are usually a sufficient source. The ways of representation are variable. For example, the three main ways of linguistic representation of emotions, which are identified by the researcher N.F. Yezhova [8], include representation using:

- words nominating emotions,

- words describing them,

- using emotive means.

Emotive tools for analyzing digital footprint include emoji, stickers, static and gif images, punctuation marks expressing emotions (exclamation marks, dots, etc.), the use of Caps Lock to express emotions, and so on. A fragment of the specification can be seen in table 3.

Table 3. Specification of factors (fragment).

\begin{tabular}{|c|l|l|}
\hline \multicolumn{2}{|c|}{ Factor } & \multicolumn{1}{|c|}{ Expectation factors } \\
\hline$\#$ & \multicolumn{1}{|c|}{ Specification } \\
\hline 1 & Neuroticism & $\begin{array}{l}\text { Emoji that express sadness and punctuation marks that equal } \\
\text { them } \\
\text { Anxiety, panic, fear, failure, lonely, sad, unhappy, always, } \\
\text { never, finally, can't, don't, won't } \\
\text { Punctuation marks: three dots }\end{array}$ \\
\hline 2 & Extraversion & $\begin{array}{l}\text { Emoji that express okay and punctuation marks that equal } \\
\text { them } \\
\text { Come on, let's, great, congratulations, address by name } \\
\text { Punctuation marks: often the sentence does not end with a } \\
\text { precept } \\
\text { Messages are short }\end{array}$ \\
\hline
\end{tabular}




\begin{tabular}{|l|l|l|}
\hline 3 & Openness & The idea is divided into few messages \\
\hline 4 & Friendliness & $\begin{array}{l}\text { Using emotions twice more than regular users } \\
\text { Humor, invented, developed, created, discovered } \\
\text { Punctuation marks: exclamation marks with smiles (not } \\
\text { aggressive) }\end{array}$ \\
\hline 5 & Conscientiousness & $\begin{array}{l}\text { Emoji that express smiles, good mood and punctuation marks } \\
\text { that equal them } \\
\text { Thank you, good luck, how are you, all the best, friends, } \\
\text { sorry }\end{array}$ \\
\hline
\end{tabular}

To develop the specification of factors, individual dialogues were manually analyzed, selected in random order. The total volume of the analyzed text was 20,000 characters.

\section{Results}

Diagnostics of 18 people - potential candidates for participation in the project team made it possible to form a set of team expectations \& avoidances. Graph 1 shows the median ranks of the choice of specific expectation \& avoidance in the team (Fig.1).

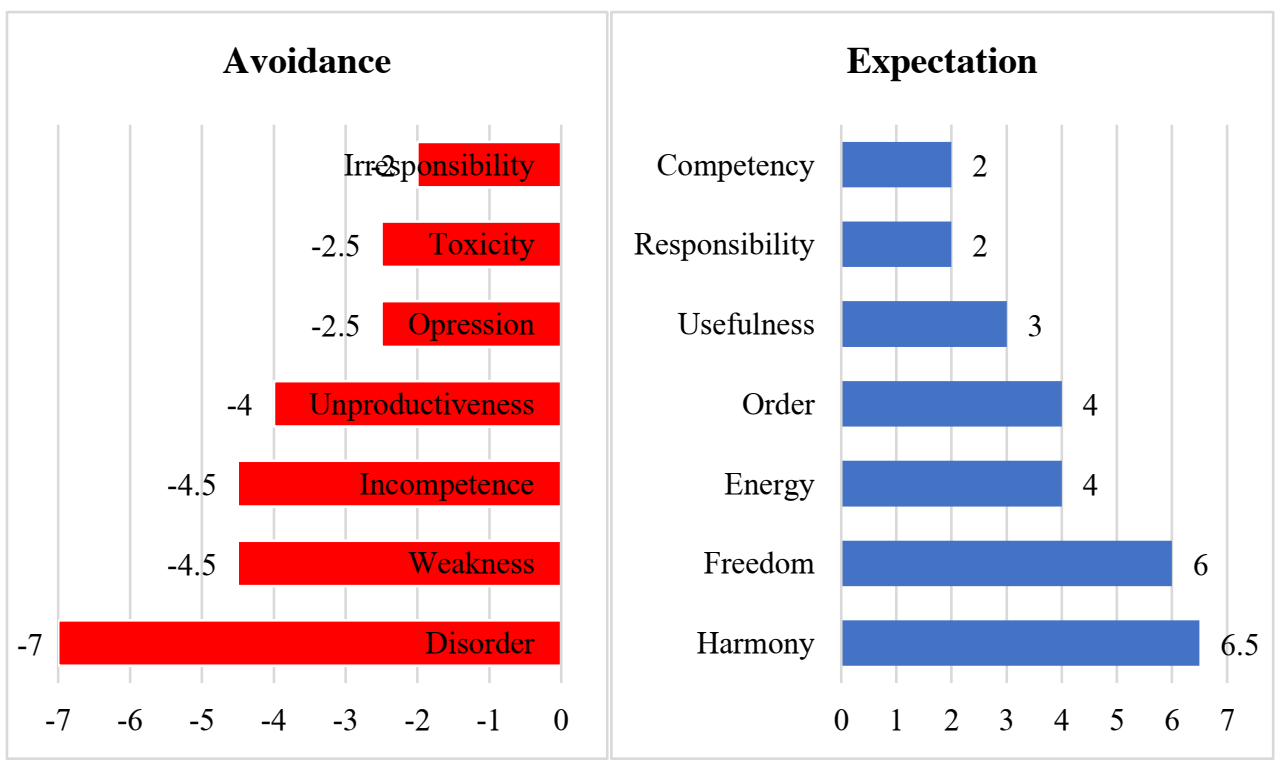

Fig. 1. Set of team expectations and avoidances.

As can be seen from Fig. 1, the tops coincide in characteristics. Most of all, this team in their work expects from each other competence and responsibility in their work, so that no one throws off someone else's work. They avoid being irresponsible and toxic (crying, spreading gossip, cheating on someone, behaving dishonestly and affecting other team members negatively), as well as any harassment. The graph shows that expectations are more consistent than avoidances but understanding and interpretation may differ. This technique can be algorithmically modeled into the instrument. 


\section{Discussion}

The proposed technique undoubtedly has a number of limitations. The methodology proceeds from the limited human resources, while significantly neglecting the goals and objectives of the project. In fact, the methodology requires the assumption that the qualifications and available free time of all potential project team members already meet the requirements.

In this regard, the developed methodology may be more relevant when recruiting personnel into an existing team. For this, a clear portrait of the team must first be formed. It is necessary to determine what are the main expectations \& avoidances for the current team members. To do this, we analyze the existing team by a set of characteristics, and then we look at how well each candidate is suitable. An example of methodology adaptation is presented in Table 4.

Table 4. Adaptation of the methodology when recruiting members of an existing team.

\begin{tabular}{|l|c|c|c|c|c|c|c|c|c|c|c|c|c|c|}
\hline & \multicolumn{1}{|c|}{ Expectation } & \multicolumn{1}{|c|}{ Avoidance } \\
\cline { 2 - 14 } & $\mathbf{1}$ & $\mathbf{2}$ & $\mathbf{3}$ & $\mathbf{4}$ & $\mathbf{5}$ & $\mathbf{6}$ & $\mathbf{7}$ & $\mathbf{1}$ & $\mathbf{2}$ & $\mathbf{3}$ & $\mathbf{4}$ & $\mathbf{5}$ & $\mathbf{6}$ & $\mathbf{7}$ \\
\hline Candidate 1 & 1 & 5 & 2 & 4 & 3 & 7 & 6 & 5 & 4 & 1 & 2 & 3 & 6 & 7 \\
\hline Candidate 2 & 2 & 3 & 4 & 1 & 6 & 5 & 7 & 4 & 3 & 5 & 1 & 2 & 7 & 6 \\
\hline Candidate 3 & 2 & 4 & 3 & 7 & 1 & 5 & 6 & 5 & 3 & 2 & 1 & 4 & 6 & 7 \\
\hline Candidate 4 & 7 & 5 & 6 & 1 & 2 & 4 & 3 & 4 & 6 & 5 & 3 & 1 & 2 & 7 \\
\hline Member 1 & 2 & 3 & 4 & 1 & 6 & 5 & 7 & 4 & 3 & 1 & 5 & 2 & 6 & 7 \\
\hline Member 2 & 1 & 2 & 3 & 7 & 6 & 4 & 5 & 5 & 3 & 4 & 1 & 2 & 6 & 7 \\
\hline Member 3 & 1 & 2 & 3 & 7 & 5 & 4 & 6 & 4 & 2 & 5 & 1 & 3 & 7 & 6 \\
\hline Member 4 & 2 & 3 & 4 & 1 & 6 & 5 & 7 & 5 & 6 & 1 & 2 & 3 & 4 & 7 \\
\hline Member 5 & 2 & 3 & 3 & 1 & 5 & 4 & 6 & 4 & 3 & 2 & 1 & 2 & 6 & 7 \\
\hline Member 6 & 1 & 4 & 3 & 7 & 2 & 6 & 5 & 5 & 2 & 3 & 1 & 4 & 6 & 7 \\
\hline Member 7 & 2 & 7 & 4 & 1 & 3 & 5 & 7 & 3 & 4 & 5 & 1 & 2 & 7 & 6 \\
\hline Member 8 & 2 & 3 & 5 & 1 & 6 & 4 & 7 & 4 & 3 & 1 & 5 & 2 & 7 & 6 \\
\hline Member 9 & 1 & 2 & 4 & 7 & 3 & 6 & 5 & 4 & 3 & 5 & 2 & 1 & 6 & 7 \\
\hline
\end{tabular}

The portrait of the team is rather homogeneous, the amplitude of fluctuations is \pm 1 . Candidate analysis identifies Candidates 2 and 3 as the most appropriate for the current team. Candidate 1 fits well in terms of expectations, but absolutely does not match in terms of avoidance. Since expectations are more important than avoidances, this candidate is a reserve in case more than 2 new team members are required or someone from the selected ones for various reasons does not fall into team. Candidate 4 absolutely does not match the characteristics and is not recommended for inclusion.

Obviously, the completely identical people should not be recruited to a team. Productive work requires differences, but these differences should not be diametrically opposed. The permissible level of harmony (spread) in our case was \pm 1 .

\section{Conclusion}

The problem of team acquiring is important while intensification of project work in all branches of activity. The labor market is quite active and dynamic, but the period of the coronavirus crisis has formed and approved new formats of remote work. Previously, it was believed that project work in a remote format was much less effective than with direct communication. However, economic realities forced to look for new ways and channels of communication, including those involving contact work with the project team.

The proposed methodology reduces the potential for conflict, and also helps to identify potential candidates focused on the qualities required for remote work: responsibility and 
order. However, the methodology has a significant limitation, which implies the initial sufficient competence of all candidates and their availability for participation.

\section{References}

1. Y. Chiu, An introduction to the History of Project Management: From the Earliest Times to A.D.1900 (Eburon, Delft, 2010)

2. S. Manning, International Journal of Project Management 26(1), 30-37 (2008)

3. PMBOK Guide $6^{\text {th }}$ edition (2017)

4. A. Mottaeva, J. Stepanova, N. Meshkova, G. Semenova, European Journal of Sustainable Development 10(1), 705-723 (2021) Doi: 10.14207/ejsd.2021.v10n1p705

5. J. McGrath, Social psychology: a brief introduction (Holt, Rinehart \&Winston, New York, 1964)

6. R.R. McCrae, P. Costa, A Five-Factor Theory of Personality. Handbook of personality: Theory and research (Guilford, New York, 1999)

7. E. Anoshkina, E. Markovskaya, A. Mottaeva, As. Mottaeva, E3S Web of Conferences 210, 13022 (2020) https://doi.org/10.1051/e3sconf/202021013022

8. N.F. Yezhova, VSU Bulletin. Humanitarian sciences 2, 10-21 (2003) 